Research Article

\title{
Employee Voice, Employee Engagement and Business Performance: Understanding the links in a Mediated Model
}

\author{
Kabiru Maitama Kura ${ }^{1, *}$ and Mohamed Alkashami ${ }^{2}$ \\ ${ }^{1}$ Universiti Teknologi Brunei, Brunei Darussalam \\ kabiru.kura@utb.edu.bn \\ ${ }^{2}$ Arab Open University, Bahrain Branch, Bahrain \\ alkashami77@gmail.com \\ *Correspondence: kabiru.kura@utb.edu.bn
}

Received: 18 ${ }^{\text {th }}$ May 2021; Accepted: 19 ${ }^{\text {th }}$ July; Published; $1^{\text {st }}$ August 2021

Abstract: Employee voice which refers to the collective bargaining of employees in an organization, is gaining much attention and importance. Studies are linking the role and relationship between employee voice with many important individual and organizational outcomes. To understand its current state and influence, the present study tested employee voice and its influence on employee engagement and business performance. Following the relationship hypothesized model, the current study applied structural equation modeling using Smart PLS 3 and found a significant relationship between employee voice and business performance. In addition, the study also found significant influence of employee voice on employee engagement and business performance. The study also found that employee engagement was mediating the relationship between employee voice and business performance. The results confirm that employees who have the freedom and opportunity to share their ideas, opinions, and input in decision-making are likely to show high engagement, which contributes to increasing business performance. The study results offer important findings based on which implications are drawn for theory and practice for businesses aspiring to increase performance.

Keywords: Employee Voice; Employee Engagement; Business Performance; Voice

\section{Introduction}

The concept of employee voice has received popularity over the past three decades, referring as collective bargaining and union-ship of employees in an organization (Rees et al., 2013). However, over the years, the concept has evolved. Some recent studies now refer to it as the option of various ways employees can talk about their ideas, aspirations, and issues (Liu et al., 2010). Overall, employee voice provides an opportunity for employees to highlight issues at work with an objective to improve business functioning (Kwon et al., 2016). Hence, it can be seen as a mechanism to engage employees on matters of concern to improve decision-making, particularly regarding the ones affecting their jobs. Literature outlines that employee voice becomes fruitful when organizations uphold an environment in which employees feel comfortable giving opinions, ensuring that they will not be penalized for it (Wæraas \& Dahle, 2020). With the growing importance of this concept followed by growing openness towards employees in organizations, scholars has stepped up efforts investigating its benefits (e.g., Ullah et al., (2020). However,

Kabiru Maitama Kura and Mohamed Alkashami, "Employee Voice, Employee Engagement and Business Performance: Understanding the links in a Mediated Model", Annals of Contemporary Developments in Management \& HR (ACDMHR), Print ISSN: 2632-7686, Online ISSN: 2632-7694, pp. 10-19, Vol.3, No. 3, $1^{\text {st }}$ August 2021, Published by International Association of Educators and Researchers (IAER), DOI: 10.33166/ACDMHR.2021.03.002, Available: http://acdmhr.theiaer.org/archive/v3/v3n2/p2.html. 
much of these studies have been conducted in regions other than Asia and the Middle East (e.g., Pati et al., 2020; Wæraas \& Dahle, 2020). Therefore, there lies a major gap towards understanding its various consequences such as business performance.

Furthermore, employee engagement which is traced back to 1990s from the work of Kahn (1990), is popularly defined by researchers in occupational psychology as a healthy work-based mindset that enables employees to work with commitment, passion and energy (Schaufeli et al., 2002). Employee engagement has received attention across major work settings and job sectors, keeping in view its significance in giving enhanced results for individuals and organizations. Macey et al. (2009) has attributed engagement as focused and energetic behavior. Engaged employees are seen more contributory compared to those who are not (Shuck \& Wollard, 2010) as they invest their fullest towards achieving organizational goals (Saks, 2006). Therefore, employee engagement can be seen as a vital ingredient for any business to increase, improve, or sustain its performance. However, to what length it is connected with employee voice and can it play any mediating role towards predicting consequences such as business performance has received limited attention in Asia. Therefore, a major research gap is evident.

\section{Literature Review and Hypotheses Development}

\subsection{Employee Voice and Business Performance}

When employees have the opportunity to express themselves in the workplace, especially on issues that matter the most to them and/or related to their job, it can result in healthy outcomes. For example, a recent study has outlined that employee voice boosts organizational innovation (Rasheed et al., 2017). The study found that when employees are allowed to express their ideas and opinion, it energizes them to be creative to boosts organizational innovation. Similarly, employee voice is also found promising in increasing employee satisfaction in the study by Holland et al. (2011). In connection to organizational level outcomes, employee voice is found instrumental in predicting organizational effectiveness (Jha et al., 2019) and organizational performance (Kim, MacDuffie \& Pil, 2010). Employee voice is also found to improve employees' mental health (Wood, 2008). Similarly, a recent study has also found a substantial role of employee voice in improving physical health (Liang, 2021), suggesting that employee voice can also have an essential role in improving elements beyond individual work, hence lending much support to the concept. These studies, therefore, suggest that employee voice can play an instrumental role. Therefore we tested the following:

\section{H1: Employee voice and business performance are positively related.}

\subsection{Employee Voice and Employee Engagement}

Employee voice is instrumental in boosting employee behaviors. Studies show that employees who feel that they have the opportunity to express their views without any hesitation in the business and that the concerned individuals/units will take their opinion positively to help resolve the issues will always be better employees than others (Kim et al., 2010; Rasheed et al., 2017). Moreover, studies also outline that employees who see a participative behavior in the company and that their ideas and opinions are valued in the business for decision-making, especially on matters concerning their job roles, are profound performers (e.g., Akinwale, 2019). Similarly, research has indicated the same for engagement, outlining that employee voice boosts employee immersion, vigor, and dedication to harness psychological well-being (Rees, Alfes \& Gatenby, 2013; Ruck et al., 2017). Though much of these studies were conducted in western economies, yet still, we perceived that it will yield similar results. Therefore we tested the following:

H2: Employee voice and employee engagement are positively related. 


\subsection{Employee Engagement and Business Performance}

Engagement refers to a positive work-based state of mind that makes employees to work with vigor, dedication and immersion (Schaufeli et al., 2002). Employees who are engaged are generally more eager to work harder and willing to go the extra mile than those who are not engaged (AlZgool et al., 2020; Reijseger et al., 2017). This evidence suggests that employees who are psychologically connected with work are better in furthering their engagement levels. In connection to performance, studies show that employee engagement results in performance outcomes (Adhitama \& Riyanto, 2020; Motyka, 2018; Bothma \& Roodt, 2012). These studies indicate that employees`engaged behaviors can perform better and much more effectively than others. Based on these evidence, we assert that engaged employees will also help businesses perform better since better-performing employees will result in a better-performing organization. Therefore we tested:

H3: Employee engagement and business performance are positively related.

\subsection{Mediation Employee Engagement}

Several studies have tested and confirmed the role of employee engagement as a mediator. Research on employee behaviors and outcomes shows how different individual and organizational factors predict employee engagement, which further leads to performance-based entities, thus confirming its mediation (Gupta, 2017; Natrajan, Sanjeev \& Singh, 2019). Therefore, we speculate that employee engagement will mediate. To discuss in detail, a recent study by Sharma and Kumra (2020) investigated the role of employee engagement as the mediator between organizational justice, workplace spirituality and mental health and reported a mediation effect. Similarly, Sendawula et al. (2018) study in the healthcare sector also confirmed the mediation effect of employee engagement. Similarly, Saks (2006) also confirmed the mediation of employee engagement in its study on its antecedents and consequences. Therefore, this evidence led us to venture that employee voice where employees experience openness in the organization towards their opinion, ideas, feedback, and suggestions to critical matters and points of concern will enhance their engagement that will increase business performance. Thus we tested:

H4: Relationship between employee voice and business performance is mediated by employee engagement.

\section{Methodology}

\subsection{Sampling and Data Collection}

Cross-sectional approach was applied in the current study to examine the relationship between employee voice, employee engagement and business performance. Keeping in view the ongoing pandemic, an online survey was created to obtain responses from the employees working in the financial sector of Brunei Darussalam. Snowball sampling technique was used in this regard whereby an electronic questionnaire was mailed to target individuals repeatedly, as suggested by Sekaran and Bougie (2016). A total of 320 employees of the financial sector were mailed repeatedly, out of which 293 responded. From the 293,8 were found inappropriate and were hence discarded. The response rate for the study turned to be $89 \%$.

\subsection{Measurement and Scales}

Employee voice was assessed using a six-item scale adapted from the studies of Botero \& Van Dyne (2009) and Van Dyne \& LePine (1998), following the footsteps of Jha et al. (2019). Similarly, employee engagement was measured adapting the nine-item scale by Schaufeli et al. (2006), following the footsteps of Ahmed et al. (2021). Lastly, business performance was assessed by adapting a three-item scale from Deshpande et al. (1993) and a four-item scale from Jaworski and Kohli (1993), following the footsteps of 
Umrani et al. (2018). The study used a seven-point Likert scale ranging from 1 as strongly disagree to 7 as strongly agree.

\subsection{Analyses}

The hypotheses of the study were examined via Smart PLS 3 (Ringle et al., 2015). The study applied the structural equation modeling technique with a two-stage approach as recommended by Hair et al. (2011). PLS path modelling approach has received wide spread appreciation due to its predictability and suitability when it comes to performing any analytical procedures (Rigdon, 2012). The two-stage approach caters to the assessment of measurement model and assessment of the structural model.

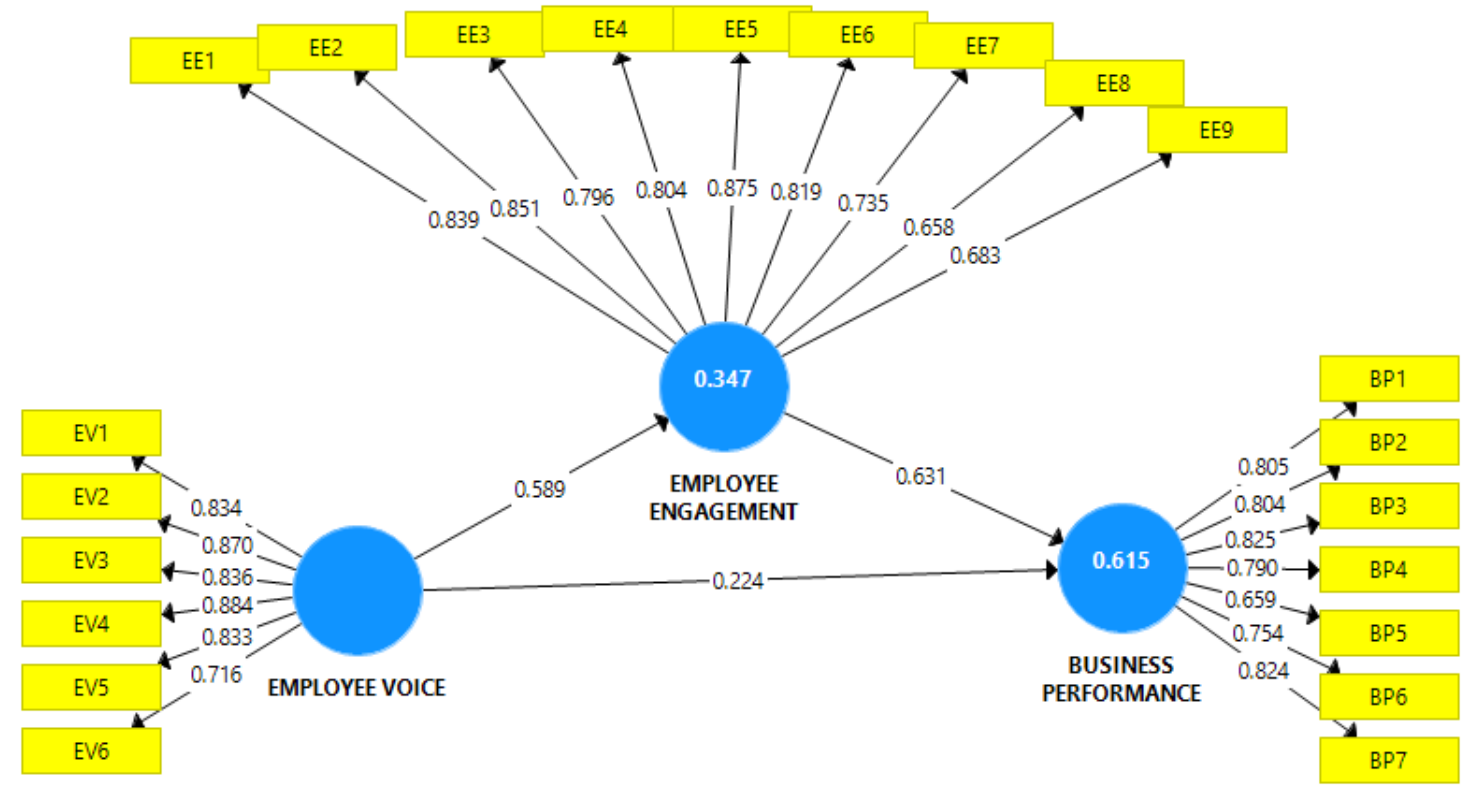

Figure 1. Measurement Model

\section{Results}

\subsection{Assessment of Measurement Model}

Measures in the current study were used to assess reliability and validity well before assessing the structural equation modeling (SEM). Alpha coefficient of all variables was assessed and found well above the recommended range of $(\alpha>0.70)$, which meets the reliability criteria. Table 1 shows adequate validity of all variables as average variance extract scores exceeded 0.50 and composite reliability scores were also higher than 0.70 as recommended in Hair et al. (2006).

Table 1. Loading, alpha, Composite Reliability, Average Variance Extract

\begin{tabular}{lcccc}
\hline Construct & Loading & $\alpha=$ alpha & CR & AVE \\
\hline Employee Voice & & 0.910 & 0.930 & 0.690 \\
EV1 & 0.834 & & & \\
EV2 & 0.870 & & & \\
EV3 & 0.836 & & \\
EV4 & 0.884 & & \\
EV5 & 0.833 & 0.922 & & .621 \\
EV6 & 0.716 & & \\
Employee Engagement & & & \\
EE1 & 0.839 & & \\
EE2 & 0.851 & & \\
EE3 & 0.796 & &
\end{tabular}




$\begin{array}{ll}\text { EE4 } & 0.804 \\ \text { EE5 } & 0.875 \\ \text { EE6 } & 0.819 \\ \text { EE7 } & 0.735 \\ \text { EE8 } & 0.658 \\ \text { EE9 } & 0.683 \\ \text { Business Performance } & \\ \text { BP1 } & 0.805 \\ \text { BP2 } & 0.804 \\ \text { BP3 } & 0.825 \\ \text { BP4 } & 0.790 \\ \text { BP5 } & 0.659 \\ \text { BP6 } & 0.754 \\ \text { BP7 } & 0.824\end{array}$

\subsection{Assessment of Discriminant Validity}

According to Hamid, Sami, and Sidek (2017), assessment of discriminant validity much important to research. In variance-based structural equation modelling, discriminant validity is assessed through Fornell and Larcker's (1981) criteria of the square root of AVE and cross-loadings (Henseler, Ringle \& Sarstedt, 2015). Using different approaches can bring variation in results. These approaches may not detect adequacy in discriminant validity in common research grounds (Henseler, Ringle \& Sarstedt, 2015). Keeping in view the trends, Henseler, Ringle and Sarstedt (2015) recommended HTMT criteria to assess the discriminant validity. Based on the recommendations current study assessed discriminant validity through square root of AVE refer to table 2.

Table 2. Discriminant Validity

\begin{tabular}{lccc}
\hline & Business Performance & EmP: Eng & Epm:voice \\
\hline Business Performance & $\mathbf{0 . 7 8 2}$ & & \\
EmP: Eng & 0.763 & $\mathbf{0 . 7 8 8}$ & \\
Epm:voice & 0.595 & 0.589 & $\mathbf{0 . 8 3 1}$ \\
\hline
\end{tabular}

Bold values show square root of AVE

Besides the square root of AVE, the current study also checked HTMT criteria for discriminant validity. Scholars have recommended different benchmarks for HTMT values. For example, Clark and Watson (1985) and Kline (2011) recommend HTMT0.85 as the threshold. Teo, Srivastava and Jiang (2008) and Gold, Malhotra, and Segars (2001) recommend a threshold of HTMT0.90. Results in Table 3 illustrate HTMT values where they were found below the HTMT0.85 threshold, showing an adequate level of discriminant validity.

Table 3. Discriminant Validity (HTMT criteria)

\begin{tabular}{lccc}
\hline & Business Performance & EmP: Eng & Epm:voice \\
\hline Business Performance & --- & & \\
EmP: Eng & 0.833 & --- & \\
Epm:voice & 0.656 & 0.632 & ---- \\
\hline
\end{tabular}

\subsection{Assessment of variance in Endogenous Variables}

According to Hair et al. (2011); (2012); Henseler, Ringle and Sinkovics (2009), R-square is the coefficient of determination and that the model can also be assessed through $\mathrm{R}^{2}$. Recommended ranges of $\mathrm{R}^{2}$ are 0.10 , 0.19 and 0.67 (Falk \& Miller, 1992). Results regarding $R^{2}$ values are illustrated in table 4, showing variance observed in business performance as $61.5 \%$ and variance in employee engagement as $34.7 \%$.

Table 4. R Square

\begin{tabular}{llc}
\hline Variable & R-Square & Adjusted R-Square \\
\hline Business Performance & 0.615 & 0.612 \\
Employee Engagement & 0.347 & 0.344 \\
\hline
\end{tabular}




\subsection{Assessment of Effect Size}

Current research also assessed the effect size of exogenous variables on endogenous. According to Chin (1998) effect size of 0.02 shows a weak effect, 0.15 shows a moderate effect, and 0.35 shows a strong effect. Results regarding effect size are illustrated in table 5A. The findings of current research show the strong effect of employee engagement on business performance. Besides this, employee voice has a strong effect on employee engagement and a weak effect on business performance.

Table 5 A. $\mathrm{f}^{2}$ Values

\begin{tabular}{lllcc}
\hline & & Business Performance & EmP: Eng & effect \\
\hline EmP: Eng & 0.676 & & strong \\
Epm:voice & 0.085 & 0.530 & weak on BP, strong on EE \\
\hline
\end{tabular}

\subsection{Assessment of predictive relevance}

After assessing variance explained in endogenous variable and effect size, the current study also assessed predictive relevance from omitted cases in data. For measuring predictive relevance (goodness of fit) current research applied the Stone-Geisser test known as blindfolding ( $\left.\mathrm{Q}^{2}\right)$ (Geisser, 1974; Stone, 1974). Henseler, Ringle, and Sinkovics (2009) recommended that Q2 values must be higher than zero for endogenous variables. The current study found Q2 values above zero in all cases and are illustrated in table $5 \mathrm{~B}$.

Table 5 B. Predictive Relevance

\begin{tabular}{llll}
\hline Variable & SSO & SSE & Q2= (1-SSE/SSO) \\
\hline Business performance & 1995 & 1255.338 & 0.371 \\
Employee engagement & 2565 & 2026.216 & 0.210 \\
\hline
\end{tabular}

\subsection{Assessment of Structural Model}

After the achievement of satisfactory results in the measurement model, the current study assessed the structural model to test the hypothesized relationships. Illustrated in table 6 and figure 2, empirical findings of the current research show a significant positive effect of employee voice on business performance $(\beta=0.224, \mathrm{t}$ value $=4.692, \mathrm{p}=0.000)$. Accordingly, the current study also found significant results of employee voice on employee engagement $(\beta=0.589, \mathrm{t}$ value $=13.993, \mathrm{p}=0.000)$. Similarly, employee engagement was also found in a significant relationship with business performance $(\beta=0.631, t$ value $=14.551 \mathrm{p}=0.000)$.

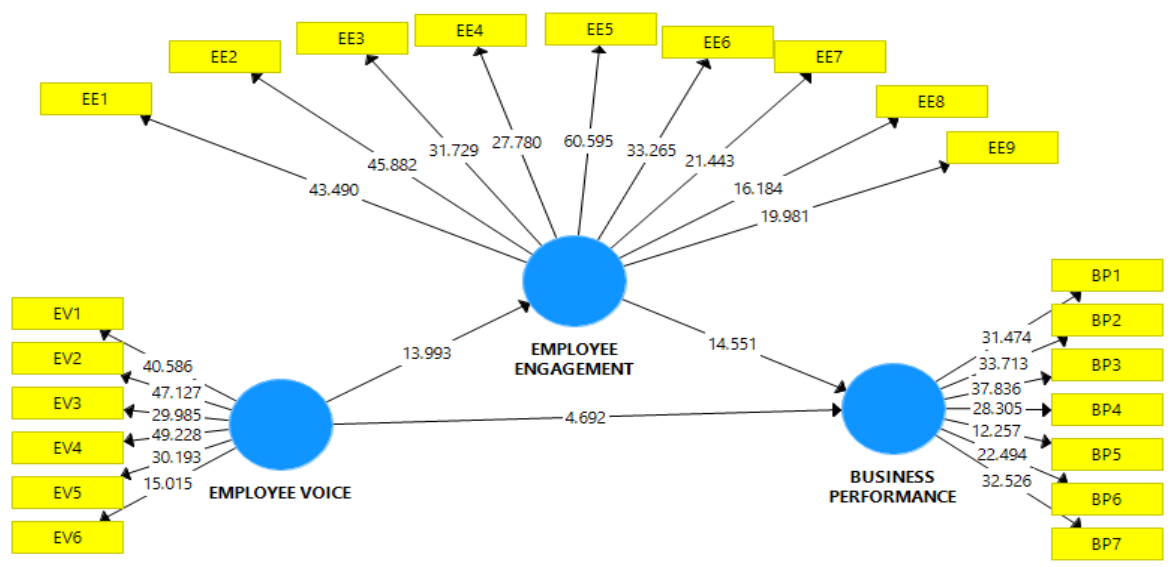

Figure 2. Structural Model

Along with the direct relationships stated earlier, the current research also assessed the mediating effect of employee engagement on the relationship between employee voice and business performance in $(\beta=0.372$, $t$ value $=9.635, p=0.000)$. Based on the research by Hayes (2009) and Preacher and Hayes (2008), 
full or partial mediation effect can be seen, occurs when there are changes in the direct relationships. Results of hypothesis 4 testing the mediation showed improvement in the $t$ value, improving from 4.692 to 9.634 . Thus, the study found significant mediation of employee engagement in the relationship between employee voice and business performance.

Table 6. Structural Model

\begin{tabular}{lllllll}
\hline Statement & Beta & Mean & STDEV & t value & p value & Decision \\
\hline H1: $E V \rightarrow$ BP & 0.224 & 0.222 & 0.048 & 4.692 & 0.000 & Accepted \\
H2: $E V \rightarrow$ EE & 0.589 & 0.591 & 0.042 & 13.993 & 0.000 & Accepted \\
H3: $\mathrm{EE} \rightarrow$ BP & 0.631 & 0.634 & 0.043 & 14.551 & 0.000 & Accepted \\
H4: $E V \rightarrow$ EE $\rightarrow$ BP & 0.372 & 0.374 & 0.039 & 9.635 & 0.000 & Accepted \\
\hline
\end{tabular}

\section{Discussion and Conclusion}

The current study tested the association between employee voice, employee engagement and business performance. At first, the study tested the association between employee voice and business performance in hypothesis one and found significant results ( $\beta$ 0.224; $\mathrm{t} 4.692)$. The results confirm the association that suggests that when employees are given the opportunity to share ideas, opinion, and participate on matters of concern related to their job matters, it helps them serve better, resulting in improving business performance. The finding also confirms the prior study of Kim et al. (2010) that landed positive indicated a positive role of employee voice towards increasing performance-based outcomes. The findings also support prior research indicating how organizational working can be improved through employee voice (Jha et al., 2019). In addition, the current study tested the association between employee voice and employee engagement in hypothesis two. The results confirmed the association suggesting that employees who have the opportunity to express their ideas, opinion and participate in the decision-making can resolve work with energy, passion, and zeal, which means increasing their engagement. The finding confirms the results of prior studies on this association (Rees, Alfes \& Gatenby, 2013; Ruck et al., 2017). Accordingly, the study also tested the association between employee engagement and business performance in hypothesis three. The results also confirmed the association suggesting that employees who were engaged with their work were more proactive in performing their job roles, enhancing their business performance. The result has been confirmed (Adhitama \& Riyanto, 2020; Motyka, 2018; Bothma \& Roodt, 2012), suggesting that employees who are engaged are better in performance which ultimately boosts business performance. Lastly, the study also founds significant mediation of employee engagement in the relationship between employee voice and business performance in hypothesis four. This confirms prior studies (Saks, 2006; Gupta, 2017; Natrajan, Sanjeev \& Singh, 2019) suggesting that employees' voice induces engagement which later contributes in predicting business performance. In other words, employees' engagement is an inner mechanism that helps employees voice to increase their performance. In conclusion, the significant results have helped the current study confirm the importance of employee voice in predicting employee engagement and business performance and the mediation of engagement in the Asian region.

\subsection{Implications}

The study has several implications for theory and practice. For theory, the study has confirmed the role of employee voice in predicting employee engagement and business performance. The study also contributed to confirm the mediation of employee engagement in the relationship between employee voice and business performance. More importantly, the study has confirmed the significance of employee voice as an important factor and its instrumentality for businesses to increase employee engagement and business performance. The study has also confirmed the contextual significance of employee voice in the Asian market. Practically, the results indicate many important implications for managers, owners and policymakers on improving business performance. We suggest five important implications based on the 
findings. First, the findings imply that employee voice where an organization gives opportunity to their employees to share their ideas, concerns, views, and opinions is important and can be seen as important in predicting much-needed employee behaviors and organizational outcomes. Based on this, we imply that employee voice should be given priority to ensure that organizations develop a feeling of belongingness and care in employees' minds, which would motivate them to work harder and concentrate on boosting performance.

For this, policy developers need to re-look into how effective procedures can be designed and established to ensure that the employees are given the opportunity to have their say in the business, particularly on matters of their concern related to the job. Second, the study implies that employee voice is an important aspect of increasing employee engagement. Based on this, the current study implies that organizations valuing engagement may need to see how they can help employees connect their voices to boost their engagement. Top management may play a key role in this by organizing and participating in the session related to opinion sharing and helping employees express their say and concern in translating into boosting engagement. Third, the study findings imply that engaged employees are better in increasing business performance. This implies an important aspect for HR management, managers, and owners to contribute by making policies that track individual performance to see how different employees perform and indicate the ones engaged and perform better than the rest. With this indication, the management may plan to reward such employees for helping them consistently showcase such results to boosts performance of the business. Fourth, the study implies that an overall strategy is needed to be devised by HR and policy makers in the Asian economies to ensure that business performance is precisely observed while indicating those contributing more compared to others. Fifth, the findings of the study also imply the need of training activities and its significance to help supervisors and managers understand how to make a better use of employee voice. In addition, learning and development activities may also be used to help employees understand how they can make better use of their psychological well-being to increase business performance. In this, we also imply establishing mutual trust and creating a healthy organizational culture where employees have no fear of sharing their opinions on matters of importance and issues related to their job. This, towards the end, will create value-based connectivity among employees, managers, and organizations to boost individual and organizational outcomes.

\subsection{Limitations and Future Research Directions}

The study has some important limitations that are highlighted for future researchers to consider while studying employee voice and its consequences. First, the study was conducted with a cross-sectional design which limits the causality of the results. Therefore, it is suggested for future researchers to apply longitudinal approach in a similar model for better understanding of the results. Second, the study was conducted in Brunei Darussalam to address the contextual gap. However, there lies a significant gap in terms of understanding the state of employee voice and its impact on employee and organizational factors in the Middle Eastern economies. Therefore, future studies may consider targeting a sample from such nations to understand the role and importance of employee voice. Also, the current study tested the mediation of employee engagement in the relationship between employee voice and business performance. Though the study found significant mediation, future studies are still advised to test the mediation in other Asian and Middle Eastern economies to confirm its intervening role. Furthermore, the current study also educates future researchers to test other factors by extending the investigated framework since the current study was limited to employee voice, employee engagement, and business performance. In addition, the current study also suggests testing the moderation of different factors in the employee voice and business performance relationship. 


\section{References}

Adhitama, J., \& Riyanto, S. (2020). Maintaining Employee Engagement and Employee Performance during Covid-19 Pandemic at PT. Koexim Mandiri Finance. Journal of Research in Business and Management, 8(3). 6-10.

Ahmed, U., Yong, I.S.-C., Pahi, M.H. and Dakhan, S.A. (2021), "Does meaningful work encompass support towards supervisory, worker and engagement relationship?", International Journal of Productivity and Performance Management, ahead-of-print. https://doi.org/10.1108/IJPPM-06-2020-0321

Akinwale, O. E. (2019). Employee voice: Speaking up in organisation as a correlate of employee productivity in oil and gas industry: An empirical investigation from Nigeria. Serbian Journal of Management, 14(1), 97-121.

AlZgool, M. R. H., Ahmed, U., Pahi, M. H., \& Ammar, A. (2020). COVID-19 and Work Engagement: Understanding the Nexus of Leaders Emotional Intelligence, Self-efficacy and Resilience in the Banking Sector of Bahrain. Revista Argentina de Clínica Psicológica, 29(3), 568-586

Botero, I. C., \& Van Dyne, L. (2009). Employee voice behavior: Interactive effects of LMX and power distance in the United States and Colombia. Management Communication Quarterly, 23(1), 84-104.

Bothma, F. C., \& Roodt, G. (2012). Work-based identity and work engagement as potential antecedents of task performance and turnover intention: Unravelling a complex relationship. SA Journal of Industrial Psychology, 38(1), $27-44$.

Chin, W. W. (1998). The partial least squares approach to structural equation modeling. Modern Methods for Business Research, 295(2), 295-336.

Clark, L. A., \& Watson, D. (1995). Constructing validity: basic issues in objective scale development. Psychological Assessment, 7(3), 309-319.

Deshpandé, R., Farley, J. U., \& Webster Jr, F. E. (1993). Corporate culture, customer orientation, and innovativeness in Japanese firms: a quadrad analysis. Journal of Marketing, 57(1), 23-37.

Falk, R. F., \& Miller, N. B. (1992). A Primer for Soft Modeling. Ohio: The University of Akron Press.

Fornell, C. G., \& Larcker, D. F. (1981). Evaluating structural equation models with unobservable variables and measurement error. Journal of Marketing Research, 18(1), 39-50.

Geisser, S. (1974). A predictive approach to the random effect model. Biometrika, 61(1), 101-107.

Gold, A. H., Malhotra, A., \& Segars, A. H. (2001). Knowledge management: an organizational capabilities perspective. Journal of Management Information Systems, 18(1), 185-214.

Gupta, M. (2017). Corporate social responsibility, employee-company identification, and organizational commitment: Mediation by employee engagement. Current Psychology, 36(1), 101-109.

Hair, J. F., Ringle, C. M., \& Sarstedt, M. (2011). PLS-SEM: Indeed, a silver bullet. Journal of Marketing Theory and Practice, 19(2), 139-152.

Hair, J. F., Sarstedt, M., Pieper, T. M., \& Ringle, C. M. (2012). The use of partial least squares structural equation modeling in strategic management research: a review of past practices and recommendations for future applications. Long Range Planning, 45(5-6), 320-340

Hair, J.F., Black, W.C., Babin, B.J., Anderson, R.E. \& Tatham, R.L. (2006), Multivariate Data Analysis, Pearson University Press, New Jersey, NJ.

Hamid, Ab. M.R., Sami, W., \& Sidek, MH. M. (2017, September). Discriminant validity assessment: Use of Fornell \& Larcker criterion versus HTMT criterion. In Journal of Physics: Conference Series 890(1), 012163). IOP Publishing.

Hayes, A. F. (2009). Beyond Baron and Kenny: Statistical mediation analysis in the new millennium. Communication Monographs, 76(4), 408-420.

Henseler, J., Ringle, C. M., \& Sarstedt, M. (2015). A new criterion for assessing discriminant validity in variance-based structural equation modeling. Journal of the Academy of Marketing Science, 43(1), 115-135.

Henseler, J., Ringle, C. M., \& Sinkovics, R. R. (2009). The use of partial least squares path modeling in international marketing. Advances in International Marketing, 20(1), 277- 319.

Holland, P., Pyman, A., Cooper, B. K., \& Teicher, J. (2011). Employee voice and job satisfaction in Australia: The centrality of direct voice. Human Resource Management, 50(1), 95-111.

Jaworski, B.J. \& Kohli, A.K. (1993), Market orientation: antecedents and consequences, Journal of Marketing, 57(3), 53-70

Jha, N., Potnuru, R. K. G., Sareen, P., \& Shaju, S. (2019). Employee voice, engagement and organizational effectiveness: a mediated model. European Journal of Training and Development, 43( 7/8), 699-718.

Kahn, W.A. (1990), Psychological conditions of personal engagement and disengagement at work, Academy of Management Journal, 33, 692-724. 
Kim, J., MacDuffie, J. P., \& Pil, F. K. (2010). Employee voice and organizational performance: Team versus representative influence. Human Relations, 63(3), 371-394.

Kline, R. B. (2011). Principles and practice of structural equation modeling. New York: Guilford Press.

Liang, H. L. (2021). Does workplace bullying produce employee voice and physical health issues? Testing the mediating role of emotional exhaustion. Frontiers in Psychology, 12, 1-9.

Motyka, B. (2018). Employee engagement and performance: a systematic literature review. International Journal of Management and Economics, 54(3), 227-244.

Natrajan, N. S., Sanjeev, R., \& Singh, S. K. (2019). Achieving job performance from empowerment through the mediation of employee engagement: an empirical study. Independent Journal of Management \& Production, 10(3), 1094-1105.

Preacher, K. J., \& Hayes, A. F. (2008). Asymptotic and resampling strategies for assessing and comparing indirect effects in multiple mediator models. Behavior Research Methods, 40(3), 879-891.

Rasheed, M.A., Shahzad, K., Conroy, C., Nadeem, S. \& Siddique, M.U. (2017), Exploring the role of employee voice between high-performance work system and organizational innovation in small and medium enterprises, Journal of Small Business and Enterprise Development, 24(4), 670- 688.

Rees, C., Alfes, K., \& Gatenby, M. (2013). Employee voice and engagement: connections and consequences. The International Journal of Human Resource Management, 24(14), 2780-2798.

Reijseger, G., Peeters, M. C., Taris, T. W., \& Schaufeli, W. B. (2017). From motivation to activation: why engaged workers are better performers. Journal of Business and Psychology, 32(2), 117-130.

Rigdon, E. E. (2012). Rethinking partial least squares path modeling: In praise of simple methods. Long range planning, 45(5-6), 341-358.

Ringle, C. M., Wende, S., \& Becker, J. -M. (2015). SmartPLS 3. Bönningstedt: SmartPLS GmbH. Retrieved from www.smartpls.de

Ruck, K., Welch, M., \& Menara, B. (2017). Employee voice: an antecedent to organisational engagement?. Public Relations Review, 43(5), 904-914.

Saks, A. M. (2006). Antecedents and consequences of employee engagement. Journal of Managerial Psychology, 21(7), 600619.

Schaufeli, W. B., Salanova, M., González-Romá, V., \& Bakker, A. B. (2002). The measurement of engagement and burnout: A two sample confirmatory factor analytic approach. Journal of Happiness Studies, 3(1), 71-92.

Sendawula, K., Nakyejwe Kimuli, S., Bananuka, J., \& Najjemba Muganga, G. (2018). Training, employee engagement and employee performance: Evidence from Uganda's health sector. Cogent Business \& Management, 5(1), 1470891.

Sharma, P.K. \& Kumra, R. (2020), Relationship between workplace spirituality, organizational justice and mental health: mediation role of employee engagement, Journal of Advances in Management Research, 17(5), 627-650.

Shuck, B., \& Wollard, K. (2010). Employee engagement and HRD: A seminal review of the foundations. Human resource Development Review, 9(1), 89-110.

Stone, M. (1974). Cross validatory choice and assessment of statistical predictions, Journal of the Royal Statistical Society, 36(2), 111-147

Teo, T. S. H., Srivastava, S. C., \& Jiang, L. (2008). Trust and electronic government success: An empirical study. Journal of Management Information Systems, 25(3), 99-132.

Umrani, W. A., Kura, K. M., \& Ahmed, U. (2018). Corporate entrepreneurship and business performance: The moderating role of organizational culture in selected banks in Pakistan. PSU Research Review. 2(1), 59-80.

Ullah, I., Kayani, N. Z., \& Mahmood, A. (2020). Fostering innovative performance through ethical leadership: examining the mediating role of employee voice. European Journal of International Management, 14(4), 672-692.

Van Dyne, L., \& LePine, J. A. (1998). Helping and voice extra-role behaviors: Evidence of construct and predictive validity. Academy of Management Journal, 41(1), 108-119.

Wæraas, A., \& Dahle, D. Y. (2020). When reputation management is people management: Implications for employee voice. European Management Journal, 38(2), 277-287.

Wood, S. (2008). Job characteristics, employee voice and well-being in Britain. Industrial Relations Journal, 39(2), 153-168.

(C) 2021 by the author(s). Published by Annals of Contemporary Developments in Management \& HR (ACDMHR), under the terms and conditions of the Creative Commons Attribution (CC BY) license which can be accessed at http://creativecommons.org/licenses/by/4.0. 